\title{
Limitações e possibilidades institucionais: a formação inicial em Educação Física - Licenciatura
}

http://dx.doi.org/10.11606/1807-5509202000040735
Camila Rinaldi Bisconsini * Juliana Pizani ${ }^{* *}$ Amauri Aparecido Bássoli de Oliveira *
*Departamento de Educação Física, Universidade Estadual de Maringá, Maringá, PR, Brasil.

**Departamento de Educação Física, Universidade Federal de Santa Catarina, Florianópolis, SC Brasil.

\section{Resumo}

0 objetivo foi verificar quais limitações enfrentam professores e acadêmicos de um curso de licenciatura em educação física para aproximar universidade e escola ao longo da formação inicial, bem como as possibilidades para integrar estas instituições e contribuir para a imersão dos futuros professores na educação básica. É uma pesquisa qualitativa e descritiva que se deu a partir do estudo de caso em uma universidade pública do estado do Paraná, com 18 docentes e 41 egressos da licenciatura em educação física. Todos participaram de uma entrevista semiestruturada, cujo conteúdo foi investigado por meio da análise de conteúdo com suporte do software NVivo 10. A perspectiva apresentada revela que as barreiras institucionais, para qualificar a formação inicial por meio de atividades pedagógicas integradas ao ambiente escolar, são mais expressivas do que as possibilidades existentes para estreitar a comunicação entre os níveis de ensino básico e superior. Mesmo assim, nenhum dos registros mostrou radicalidade; apesar das barreiras expostas, os professores se mostram predispostos a propor ou incorporar propostas formativas mais próximas da realidade interventiva dos professores de educação física que atuam no cenário escolar.

Palavras-chave: Educação Física; Formação docente; Ensino; Escola.

\section{Introdução}

O Ensino Superior e a Educação Básica compóem a formaçáo social, cujas relaçóes envolvem o sistema de ensino institucionalizado, a intervenção pedagógica e os agentes responsáveis por ensinar e os que buscam aprender certo conjunto de conhecimentos. Contudo, essa formação não é objetiva, tão pouco uniforme, mas repleta de pontos comunicativos formados por inter-relaçôes - consistentes ou frágeis - que dependem fortemente dos agentes, suas disposiçôes e capitais específicos ${ }^{1}$. As intençôes e açôes de professores e alunos (além dos aspectos estruturais) poderão refletir os conflitos, as direções formativas e, no fim do processo, a organização e o andamento de todo o sistema de ensino. Para compreender essa dinâmica é preciso explorar estudos que abordem diferentes aspectos desse sistema (análises sociológicas, atividades pedagógicas específicas, entre outros).

A partir de uma crítica com riqueza de detalhes e relaçóes, Bourdieu e Passeron ${ }^{1}$ denunciam os meios de reprodução do arbitrário cultural dominante por meio do sistema de ensino. Para tanto, definem e intercruzam conceitos que incluem o trabalho pedagógico, mediado pela autoridade pedagógica detida pelos agentes que intervêm profissionalmente nas instâncias de ensino; e o trabalho escolar, que contribui para reforçar a formação dos grupos sociais dominantes. Em outras palavras, os autores descortinam fundamentos ocultos de dominação que passam pelo habitus primário (no convívio familiar principalmente) e pela ação pedagógica primária, intensificada na escola, já que na perspectiva apresentada, tendem a ter êxito nesta instituiçâo aqueles que possuem maior capital 
econômico e cultural antes mesmo de frequentá-la.

Apesar da multiplicidade de produçóes, Pierre Bourdieu reitera suas principais formulaçóes para abordar os diferentes - e interligados - fenômenos sociais que se propôs a analisar. Dentre esses conceitos se destacam o habitus (conjunto de disposições duráveis orientadoras da ação), campo (espaço social de concorrências e posiçóes distintas) e capital (referências adquiridas para integrar um campo). Entre outros fins, sua intenção era provocar os leitores para uma interpretação social diferente do que se revela à primeira vista e desvelar fundamentos não declarados. Nesse caminho, analisar e transformar quaisquer processos ou práticas pressupóe compreender essas dinâmicas a partir dos agentes que as integram e das relaçóes que são constituídas no espaço social investigado. Ou seja, como estudar o processo de formação inicial docente sem enxergar o campo universitário em seus conflitos e a partir de seus agentes? Destacam-se, portanto, as pesquisas que se propóem a revelar os condicionantes envolvidos na dinâmica dos fenômenos por meio dos próprios envolvidos.

Engendrar o conjunto de conhecimentos que constituirá currículos em cursos de Licenciatura em Educação Física requer um olhar amplo sobre as diversas práticas corporais de que trata a área e, mais que isso, a consideração do contexto para o qual está formando. Uma composição curricular que se pretenda crítica pressupóe uma relação dialética entre o repertório de formulações científicas reconhecidas na área e as novas demandas que cotidianamente emergem nos ambientes de ensino institucionalizados. Portanto, pensar estratégias que possibilitem conhecer de perto a prática docente em escolas é um passo importante para concretizar as propostas curriculares direcionadas à formação de professores.

Algumas pesquisas têm demonstrado a primordialidade de debate acerca das iniciativas em desenvolvimento que visam a aproximação e articulação entre a universidade e as escolas públicas, estreitando a comunicação e associação dos saberes disciplinares com os experienciais e vice-versa $\mathrm{a}^{2-12}$.

Sob essa ótica, a presente pesquisa está pautada na defesa da necessidade de evidenciar, expor e analisar as impressóes dos professores e acadêmicos acerca das dificuldades e possibilidades institucionais que estabelecem ou fraturam as barreiras que podem estar dificultando o trabalho docente que, por sua vez, desempenha o papel de integrar os futuros professores ao espaço social interventivo no decorrer da formação inicial. Estas açóes buscam desvelar o trabalho pedagógico permeado no curso, bem como destacar os condicionantes envolvidos para efetivação do processo.

A compreensão do campo universitário se revela como um caminho para analisar fenômenos vinculados à formação inicial em educação física e apontar as relaçôes com escolas públicas oportunizadas nesta fase, bem como, as limitações e as condiçóes institucionais que impulsionam ou retardam açóes pedagógicas diferenciadas para qualificar o processo formativo. Nesse sentido, a Universidade é um espaço social que precisa ser considerado a partir das relaçóes entre os agentes que o integram e suas disposições, já que este é o contexto em que se desenvolvem os cursos de Licenciatura e se apresentam os conflitos a serem compreendidos e discutidos.

A atividade pedagógica institucionalizada veiculada em cursos de licenciatura em Educação Física, entre outros elementos, é conduzida conforme direcionamentos legais e a partir das ideologias dos docentes e de como interpretam os objetivos formativos. Apesar de existirem grupos que não partilham de certos referenciais para subsidiar suas intervençôes, o Projeto Pedagógico do curso deveria representar uma posição coletiva acerca do perfil profissional que o corpo docente pretende formar, de modo a trabalharem conjuntamente para uma formação de qualidade, que vá ao encontro das peculiaridades profissionais. Todavia, as tensóes existentes nesse espaço que marcam a estrutura do campo universitário, podem fragilizar ou inviabilizar iniciativas de diversificação das açóes pedagógicas junto aos discentes.

As intervençóes que podem contribuir para aproximar os futuros professores da realidade docente em escolas públicas incluem a Prática como Componente Curricular ${ }^{13}$, o estágio supervisionado, o programa de iniciação à docência, projetos de extensão, eventos, entre outros. Contudo, há pesquisas indicando que ainda há o 'choque com a realidade' quando os licenciandos em Educação Física têm seus primeiros contatos com a escola no papel de professor ${ }^{14-20}$. Nesse sentido, quais são os reveses enfrentados para planejar e/ou implementar as estratégias pedagógicas de inserção no contexto escolar? E, quais são as possibilidades para intensificar a articulação entre as instâncias de ensino básico e superior? Para tanto, o objetivo foi verificar quais limitaçóes enfrentam professores e acadêmicos de um curso de Licenciatura em Educação Física para aproximar Universidade e escola ao longo da formação inicial, bem como as possibilidades para integrar estas instituiçóes de ensino e contribuir para a imersão dos futuros professores na Educação Básica. 


\section{Método}

A pesquisa é qualitativa ${ }^{21}$ e descritiva com características do estudo de caso, pelo fato de a investigaçáo ter sido realizada junto a um curso de Licenciatura em Educação Física de uma Universidade pública do estado do Paraná. Todos os egressos ( $f 41$, sendo 22 mulheres e 19 homens) matriculados em 2016 participaram da pesquisa, bem como 18 professores permanentes do mesmo curso (oito mulheres e dez homens, três mestres e 15 doutores - com tempo de atuação entre um e 36 anos na instituiçáo investigada).

O instrumento para coleta de dados foi a entrevista semiestruturada, pois possibilitou a abordagem dos pontos referentes à pesquisa com a manutenção do fluxo normal das falas e opinióes, as quais surgiram de forma espontânea ao mesmo tempo que atenderam os objetivos propostos no estudo. Conforme LÜDKE e ANDRÉ ${ }^{21}$, a entrevista semiestruturada situa-se entre a entrevista estruturada (não amplia as questóes) e a não estruturada (fala livre), e desenvolve-se a partir de um esquema básico náo aplicado de forma fixa, o que permite adequaçóes pelo entrevistador. Vale destacar o perfil de interaçáo que possui a entrevista, pois, diferente de outros instrumentos que definem uma relaçáo hierárquica entre os pesquisados e o pesquisador, esse tipo de entrevista caracteriza-se pela interação entre os participantes - respondentes e pesquisador - o que cria uma situação de influência recíproca entre quem pergunta e quem responde. A entrevista permitiu alcançar elementos novos, os quais não eram esperados, mas que contribuíram para a análise do fenômeno investigado. Portanto, o tipo de entrevista mais coerente com a pesquisa qualitativa na educação é a menos estruturada.

Os roteiros que orientaram as entrevistas foram elaborados pelos próprios pesquisadores a partir de matrizes que contavam com três colunas organizadas do seguinte modo: 1) objetivos específicos da pesquisa; 2) indicadores de análise; e 3 ) as respectivas questóes (nas matrizes foram elaboradas no formato de perguntas e nos roteiros foram apresentadas como pontos norteadores de análise, a fim de respeitar o formato da entrevista semiestruturada que não conta com perguntas diretas em uma ordem fixa). Como a presente pesquisa integra um estudo maior, o roteiro destinado aos professores foi composto por dez temas geradores ${ }^{a}$ e àquele formulado para os acadêmicos tinha nove pontos de indagação todos relacionados à formaçáo inicial em Educação Física e às práticas de integração entre Universidade e escolas ao longo desse processo. Para o tema aqui abordado as questóes levantadas ${ }^{c}$ diziam respeito às limitaçôes e possibilidades que os docentes e discentes percebiam na elaboração e no desenvolvimento de açóes que buscam aproximar os futuros professores $\mathrm{da}$ realidade interventiva, a exemplo da Prática como Componente Curricular, dos estágios, projetos, eventos, etc. Todos foram entrevistados individualmente e as gravaçóes foram somente em áudio, com posterior transcrição e envio aos participantes para que lessem e validassem os arquivos referentes às falas.

Para a análise dos dados houve o suporte do software NVivo 10, no qual as entrevistas (fontes) foram organizadas e interpretadas, com codificação das respectivas unidades de registro direcionadas para as categorias (nós e sub-nós) pré-estabelecidas conforme o objetivo do estudo, além daquelas que emergiram ao longo das falas. A análise de conteúdo ${ }^{22}$, deuse pelas fases de pré-análise, exploração do material, tratamento dos resultados, inferência e interpretação. Essas etapas integradas abarcam a seleção das fontes, a exploração do material, a codificação em unidades de registro, o agrupamento em categorias, a descrição das categorias e a interpretação dos resultados. Tanto a categorizaçáo quanto a codificaçáo fazem parte da análise de conteúdo, em que na segunda são selecionadas as unidades de registro e na primeira estes mesmos fragmentos são agrupados conforme suas características. O nó principal foi denominado 'limitaçóes e possibilidades institucionais' e os nós secundários foram 'escola' e 'universidade', já que estas são as instituiçôes sobre as quais remetiam os diversos argumentos que emergiram a partir das questóes norteadoras.

Para garantir o anonimato dos sujeitos participantes da pesquisa, ao longo da apresentação dos resultados, os acadêmicos serão identificados pela letra "A" e os professores pela letra "P", seguidos por números sequenciais.

Todos os participantes assinaram o Termo de Consentimento Livre e Esclarecido, de modo que o projeto que abarcou a presente pesquisa passou por análise do Comitê Permanente de Ética em Pesquisa com Seres Humanos e foi aprovado no Parecer no 1.710 .582$. 


\section{Resultados e Discussão}

Considerando que um dos objetivos da formação docente é o fortalecimento ou a modificação da prática pedagógica, é essencial que os professores contem com o apoio institucional. Ao tratar da intervenção de docentes universitários, Junges e Behrens ${ }^{23}$ esclarecem que quaisquer iniciativas que visem qualificar o trabalho pedagógico demandam, em certa medida, que a instituição formadora forneça o suporte necessário para as mudanças sugeridas. Nesse sentido, vale destacar a perspectiva dos agentes envolvidos na rotina do programa de formação, pois no dia a dia vivem e integram os conflitos do campo universitário, e por isso podem revelar os detalhes que limitam ou impulsionam suas açóes.

No entanto, é importante esclarecer que esses movimentos nem sempre são percebidos pelos agentes que os compóem, pois segundo Bourdieu e PASSERON $^{1}$, a verdade objetiva é difícil de perceber, com meandros opacos, que somente se tornarão levemente mais claros se houver a oportunidade e intencionalidade de se revelarem por meio de aprofundamento teórico e analítico da realidade social, em que se aceite sua complexidade. Um passo importante para que a verdade objetiva seja revelada é duvidar das regras, questioná-las e propor outros caminhos para açóes, aparentemente, espontâneas. Uma estratégia é justamente oportunizar que os envolvidos pensem, analisem e falem sobre suas açóes e relaçóes em determinado espaço social.

Na categoria 'limitaçóes e possibilidades institucionais' há 76 referências (unidades de registro codificadas). Os docentes são os que mais comentaram o assunto, pois, ao relatar suas iniciativas pedagógicas, explicavam os motivos pelos quais determinadas atividades eram possíveis ou inviáveis, alertando para questôes específicas das instâncias de ensino. As subcategorias elencadas são 'universidade' e 'escola', pois tanto as limitaçóes quanto as possibilidades institucionais envolvem estes dois espaços, especificamente quando se trata das iniciativas que buscam integrar situaçôes da rotina escolar à formação inicial. Em outras palavras, esses condicionantes não são reservados ao ensino superior ou à educação básica, mas são provenientes de ambos.

\section{Universidade}

Para conhecer os caminhos que levam a determinadas estratégias pedagógicas em um curso de formaçâo de professores, é preciso evidenciar a perspectiva docente acerca de suas motivaçốes para decidir encaminhar as aulas de modo mais ou menos próximo da educação básica. Nesse sentido, há professores que argumentaram sobre diferentes cenários que limitam ou impulsionam certas intervençóes no curso de licenciatura em educação física. No mesmo caminho, existem acadêmicos que ressaltaram estes aspectos, corroborando posicionamentos docentes no que diz respeito à Universidade.

As dimensôes salientadas e que dizem respeito às limitações incluem: questôes burocráticas; acompanhamento docente nos encontros com as escolas; discrepância nos horários de professores universitários e da escola; escassez de carga horária docente; seguro; e, transporte.

Na universidade há dificuldades para implementação de trabalhos em nível institucional, que incluem: a falta de recursos para tocar pequenos projetos de sala de aula; a carência de oficinas, ferramentas, livros e transporte disponível para aulas práticas; etc. Além disso, outro obstáculo diz respeito aos currículos e ao modo como o conhecimento está organizado dentro de cada curso e na universidade como um todo ${ }^{24}$. Nesse sentido, existem diversos aspectos a serem coordenados pelos docentes, que precisam ser evidenciados a fim de considerar elementos envolvidos nas açóes pedagógicas do campo universitário.

Um dos pontos destacado como possível limitaçáo para de fato estruturar a ponte entre as escolas e a universidade, no papel do curso de licenciatura em educação física, é o acompanhamento dos discentes durante esses percursos, como registra a A2: "Eu acredito que talvez os próprios professores não pensam nessa hipótese, de proporcionar uma visita". Entretanto, conforme pondera a P13: "Eu percebo que nós não temos ainda, dentro desse ambiente institucional, as condiçóes para fazer todo o acompanhamento". No mesmo viés, o P19 problematiza sobre a demanda de tempo para efetivação do estágio supervisionado: "[...] não tem algo a mais, uma carga horária disponivel para os professores visitarem as escolas. [...] eu acho que é uma limitação muito grande não acompanhar todas as aulas [...] Eu acho que precisaria pensar um pouco mais na questão do tempo pra que esses professores possam estar mais presentes também na escola, carga horária, enfim, distribuição geral', e cita o estágio como responsável pela aproximação com a educaçáo básica: "Mas eu vejo essa aproximação mais direcionada ao estágio" (P19). Nesse caso, ao pensar sobre as limitaçôes ou possibilidades provocadas no campo universitário para gerar ações articuladas com as escolas, o P19 menciona o frágil acompanhamento aos discentes como barreira e indica o estágio obrigatório como encarregado de realizar essa articulação. Conforme 
Silva JúnIOR ${ }^{20}$, quando a Instituição de Ensino Superior favorece o acompanhamento e a orientação dos discentes, provoca-se discussóes críticas, debates e trocas de experiências que refletem positivamente na formação dos futuros professores.

As contribuiçóes de umadequado acompanhamento aos licenciandos quando estes se encontram em situação de exploração e experimentação no ambiente escolar, incluem: a aproximação entre a universidade e a escola por meio do compartilhamento de conhecimentos entre os agentes destas instâncias de ensino; a articulação entre os saberes experienciais e os componentes curriculares do curso; a integração do discente à realidade escolar; a possibilidade de registrar situaçóes problema e as estratégias de solução adotadas na escola, além de problematizar estes cenários nas salas de aula da universidade ${ }^{12}$.

Ainda sobre as dificuldades expostas para acompanhar os acadêmicos em possíveis observaçóes e vivências no ambiente escolar, há outros registros que ilustram essa perspectiva (adotando o estágio como referência), conforme a A19: "[...] essa aproximação entre escola e Universidade é precária, é precária. O professor consegue ir lá, conversar, visitar? Sim, mas é raro"; podemos notar essa problematizaçáo fortemente presente na fala de outros acadêmicos:

Eu cheguei à minha escola e a professora falou: 'Seus supervisores da faculdade estarão aqui?', eu falei: 'Olha, realmente eu não sei, porque são muitos alunos, essa é a realidade. Porque são muitos alunos fazendo estágio ao mesmo tempo e em várias escolas diferentes'. Às vezes essa comunicação [entre universidade e escola] fica dificil de acontecer (A23).

Nesse ano [...] ninguém foi ver meu estágio, perguntar, ir à escola. O diretor até perguntou: 'A sua professora não vem?'. A minha professora orientadora perguntou: 'Sua orientadora da faculdade não virá aqui?', falei: 'Não sei, espero que sim', mas não aconteceu (A21).

Mesmo que os pontos geradores da entrevista náo tenham incluído o estágio supervisionado do curso de licenciatura em educação física, constantemente esse era um aspecto reportado pelos entrevistados, já que é o exemplo - mais presente e sólido no curso - de comunicação entre os níveis de ensino básico e superior. De acordo com Iza e Souza Neto ${ }^{11}$, é importante que a tônica dos processos formativos seja a ação compartilhada, nesse sentido, algumas propostas de estágio se sustentam na parceria entre escolas e universidade, já que estas são instituiçôes formadoras.

Os aspectos de transporte e seguro também são indicados como limitaçóes para induzir encontros dos licenciandos com as escolas públicas. Os docentes alegam que propor atividades fora do ambiente universitário, como parte das disciplinas, requer autorização institucional, a fim de garantir respaldo legal no caso de possíveis incidentes no percurso ou mesmo no ambiente de visita ou vivência.

No QUADRO 1 são apresentadas unidades de registro que representam as perspectivas dos professores sobre as questões de transporte e seguro envolvidas nas atividades pedagógicas da universidade.

QUADRO 1 - Unidades de registro que expõem o receio dos professores em relação ao transporte e ao seguro dos acadêmicos em possíveis visitas a escolas.

\begin{tabular}{|c|c|}
\hline Professor(a) & Unidade de registro \\
\hline P1 & $\begin{array}{l}\text { Cada vez que você pede para o aluno sair da instituição, tem que ter todo um aparato de seguro, de } \\
\text { transporte, e aí isso acaba limitando [...] É possível, teria só que fazer uma reorganização de programa e } \\
\text { ementa, esse aparato legal da questáo de transporte. }\end{array}$ \\
\hline P2 & $\begin{array}{l}\text { A menos que (eu acho que não é muito correto) cada um vá com seu carro, vai como quer, como puder. } \\
\text { Quer dizer, até daria, mas o mais certo é a gente ter um ônibus da instituição que levasse os acadêmicos } \\
\text { lá para vivenciar, voltasse. }\end{array}$ \\
\hline P7 & $\begin{array}{l}\text { Eu acho que a maior limitação seria a questão da segurança. Porque você mobilizar essa comunidade, } \\
\text { os acadêmicos, para ir a campo, à escola, implica assumir essas responsabilidades de translado. Menos } \\
\text { perigoso o acadêmico ir à escola, mas há um risco, você teria que ter um seguro para esses acadêmicos. } \\
\text { Mais perigoso seria o movimento contrário, quer dizer, trazer as crianças ou para a universidade ou para } \\
\text { algum ponto. }\end{array}$ \\
\hline P16 & $\begin{array}{l}\text { Para a gente levar os alunos precisaria das questôes de seguro, para o aluno poder sair do ambiente } \\
\text { universitário e estar atuando num outro ambiente. }\end{array}$ \\
\hline P17 & $\begin{array}{l}\text { Toda vez que se tira um aluno da universidade a gente precisa ter um seguro, então ficamos um pouco } \\
\text { preocupados de tirar eles daqui. }\end{array}$ \\
\hline
\end{tabular}


Há, portanto, a preocupação dos docentes quanto aos riscos envolvidos com atividades pedagógicas que extrapolam o espaço universitário, haja vista as possíveis intercorrências que podem suceder nesse processo (translado e tempo de permanência no local - observação, vivência etc.). O P7 também alerta para os cuidados demandados com o caminho inverso, que consiste em deslocar os alunos da educação básica para a universidade para proporcionar-lhes atividades fora do ambiente escolar.

Por outro lado, uma das professoras expos um ponto de vista diferente sobre o seguro para que os acadêmicos desenvolvam atividades em outros ambientes educativos que não somente na universidade, além disso, apresentou uma possibilidade para superar tal limitação:

Eu sempre andei com os alunos pra lá e pra cá sem nunca pensar no seguro, tanto que eles foram, ano passado, visitar a escola ocupada e eu nem pensei em seguro, eu já sabia, mas eu esqueci mesmo. Então, eu acho isso ridículo, é inadmissivel, e eu já encontrei a solução pra isso, e eu não sou nada boa nessas soluçóes, mas simplesmente fazer um documento, da Pró-Reitoria de Ensino, não sei se dos recursos humanos, dizendo que, se são atividades escolares, estão liberadas (P18).

Para essa Professora a barreira do seguro pode ser superada visando uma formação diversificada e qualificada para os acadêmicos, o que implica proporcionar encontros entre estes estudantes e outros contextos que, por meio de uma intervenção pedagógica, provoquem aprendizagens que serão operadas no decorrer da atuação profissional. A mesma Professora ainda acrescenta outras impressōes sobre sua atuação no processo formativo:

Nunca deixei de entender que a minha missäo é acadêmica aqui dentro, é de produção do conhecimento, só que esse conhecimento tem que ter utilidade; e eu só vou saber se tem, quando aquelas pessoas me mostrarem o que está faltando e me ajudarem a pensar. Então pode melhorar muito, muito mesmo. $E$ há experiências fantásticas sobre a relação da universidade com a comunidade (P18).

Há a defesa de que a produçấo de conhecimento - como uma das ações dos professores universitários parta de necessidades da comunidade, no entanto, para que as demandas sejam desveladas, é preciso partilhar essa realidade, que por sua vez, requer proximidade da universidade com outros espaços sociais. Ainda, a P18 menciona que, além de expor o que está faltando, as pessoas que integram estes cenários podem contribuir com ideias para a superação de fragilidades existentes. Segundo Rios ${ }^{25: 52}$,
É importante considerar o ensino como uma prática social específica, que se dá no interior de um processo de educação e que ocorre informalmente, de maneira espontânea, ou formalmente, de maneira sistemática, intencional e organizada..$^{25}$

Também, para NeIrA ${ }^{19: 103}$, "um tema é legítimo e valioso quando emana da sociedade a qual serve e por ela é legitimado. Isso significa que todo e qualquer conhecimento pode fazer parte do currículo". Dessa forma, o ensino e a abordagem dos conhecimentos não se restringem às instituiçóes, mas podem se dar em outros espaços sociais. Esse entendimento de retroalimentação da comunidade pela universidade e vice-versa, pode contribuir para legitimar a defesa de integração entre os dois campos.

Também existem professores que apontam como barreira a carga horária das disciplinas, que por vezes não permite a diversificação dos conteúdos e das estratégias pedagógicas para abordá-los, além de dificultar a interdisciplinaridade. A P17 esclarece: "Ainda não tem uma politica aqui de formação em que a gente consiga fazer muita articulação entre os conteúdos. A disciplina tem aquela carga horária, acabou aquela carga horária, acabou a disciplina". Conforme CunHA ${ }^{24}$, a própria realidade é interdisciplinar, e no momento em que os processos pedagógicos a consideram como ponto de partida, o ensinar e o aprender se daráo mais espontaneamente.

A preocupação docente por vezes centra-se em desempenhar todos os conteúdos no espaço de tempo destinado às respectivas disciplinas, todavia, há múltiplas estratégias pedagógicas para abordar estes mesmos conteúdos, por exemplo, partindo da realidade, desenvolvendo a aula em outros espaços para além da universidade. Nesse caso não é necessário aumentar a carga horária das disciplinas, pois apenas haveria alteração dos modos de ensinar, que podem envolver a integração entre as disciplinas do curso.

O P9 ainda cita a dificuldade do desencontro entre os turnos do curso e das escolas:

\footnotetext{
Como a minha turma é do noturno, nós vamos ter que encaixar em um horário que seja compativel a todos, vai ser um desafio. Quando é a turma do integral é mais fácil, até pelo horário. Então nós vamos ter que buscar uma solução, colégios que possam abrir as portas pra que a gente desenvolva alguma atividade, alguma prática, juntamente com esses alunos.
} 
Estabelecer uma relação mais próxima com a educação básica demanda organização e planejamento, a fim de que as iniciativas alcancem os acadêmicos de todos os turnos - diurno, integral e noturno. Além disso, as propostas pedagógicas que almejam a aproximação com o âmbito escolar requerem açôes coletivas e interdisciplinares para contornar as dificuldades organizacionais. De acordo com SouzA Neto e Silva 26:898-899:

A interdisciplinaridade, junto da articulaçáo entre teoria e prática, tem sido pensada como uma das relevantes possibilidades para a superação da fragmentaçáo que se instalou no âmbito educacional. Porém, essa interdisciplinaridade abarca a interpenetração de método e conteúdo entre disciplinas que trabalham, conjuntamente, determinado objeto de estudo. Tal integraçáo ocorre durante a construção do conhecimento, de forma conjunta, desde a apresentação do problema.

Percorrer caminhos que integram os licenciandos ao seu futuro espaço interventivo envolve esforços múltiplos e integrados, que somente se consolidarão com o reconhecimento desse vínculo universidadeescola pelos docentes do curso e com a materializaçáo das propostas no currículo, bem como nas práticas do curso. Desse modo, iniciativas interdisciplinares podem ser caracterizadas como uma estratégia para minimizar as limitaçóes institucionais expostas.

Sobre os elementos burocráticos que envolvem possíveis encontros dos licenciandos com as escolas, a P8 destaca: "a burocracia é necessária, mas élimitante. Ela não fragiliza o pedagógico, mas retarda [...] deixa os alunos muito angustiados". A P13 discorre sobre essa barreira:

\section{Eu só penso que a gente deveria ter um pouco mais de agilidade nesse processo, tem que ser uma coisa muito antecipada. Demora um pouco, atrasa um pouco, qualquer iniciativa que náo seja a do estágio supervisionado obrigatório, que tem toda aquela tramitação institucional, é demorado, burocrático [...]. Eu acho que deveria ser um pouco mais ágil, não que eu ache que não tenha que ter a rigorosidade.}

Ao tratar sobre possíveis vivências dos acadêmicos em escolas, a P8 considera o rigor que permeia as atividades pedagógicas na universidade e reivindica o planejamento e a agilidade desse processo. É possível perceber que, em relação às questôes burocráticas, os registros estão fortemente relacionados ao estágio supervisionado, pois é uma ação sistematizada no curso que promove a integração entre a universidade e as escolas públicas, por isso os entrevistados se recordaram exatamente deste componente curricular quando questionados sobre as limitaçóes e possibilidades institucionais para o estreitamento da comunicação com a educação básica. Os acadêmicos ressaltam o rigor burocrático exigido para o estabelecimento legal do estágio supervisionado: "eu acho que mais questão burocrática, por ter mais trabalho, ter que ir lá, pegar papel, assinatura" (A16); "[...] pelo estágio a gente já encontra dificuldade [...] para conseguir estágio tem que passar por um monte (...) reunião" (A4).

Sobre esse aspecto, Isse e Molina NETO ${ }^{27: 6}$ afirmam que, "precisamos enfrentar o fato de que o estágio, muitas vezes, privilegia as açôes de teor utilitário, o cumprimento da carga horária e de exigências burocráticas em detrimento da reflexão pedagógica e epistemológica”. Nesse sentido, há casos em que o estágio está mais relacionado ao cumprimento de uma tarefa burocrática do que ao seu sentido fundamental ${ }^{28}$, que está relacionado à experimentação do trabalho docente, na contribuição para a constituição da identidade profissional.

Os registros alertam para o fato de que uma relação mais articulada entre universidade e escolas demandaria processos mais flexíveis, que não exigissem incontáveis documentos, assinaturas e regulamentos. Parece, portanto, que esbarrar nas questóes burocráticas é um receio dos docentes ao pensar nas possibilidades de diversificação das estratégias pedagógicas. Segundo SAVIANI ${ }^{29: 389}$, "para que o sistema [de educação] permaneça vivo e não degenere em simples estrutura, burocratizando-se, é necessário manter continuamente, em termos coletivos, a intencionalidade das açóes".

Contudo, é congruente pensar que a burocracia também se constitui como um respaldo legal para o processo, que busca garantir o amparo tanto para universidade como também para escola, sendo estas instituiçóes representadas por todos os agentes envolvidos.

Outra limitação exposta é a possível concomitância de horários entre as disciplinas no curso e as aulas da educação física escolar, o que poderia inviabilizar encontros dos acadêmicos com estes espaços. A P14 exemplifica: "Nos CMEIs , há uma concentraçâo das disciplinas no periodo da manhã, porque os professores de educação física foram lotados no periodo da manhã, e as nossas aulas presenciais são no periodo da manhã, então isso é uma dificuldade". A Professora coloca essa questão como uma barreira, todavia, poderia ser considerada como uma situação favorável à organização de atividades pedagógicas de inserção na realidade escolar, tendo um potencial indicativo para o trato do conhecimento a partir de estratégias diferenciadas, como momentos 
de observaçóes, registros e vivências em outros espaços sociais. Essa ruptura com as práticas tradicionais que ultrapassam o campo universitário é enriquecedora para o processo de ensino e aprendizagem, pois possibilita que os discentes vejam os saberes disciplinares em movimento e sintam-se partícipes do processo $^{24}$, de modo que formulem suas interpretações acerca das situações interventivas, e com a mediação docente, transitem da fase de síncrese para a fase de síntese dos conhecimentos. Em outras palavras, encontros expondo cenários reais tendem a contribuir para a ensinagem ${ }^{30}$ no curso de licenciatura em educação física, e não atrasar o cumprimento das ementas disciplinares. Os professores precisam reconhecer essas possibilidades como aliadas no ensino dos conteúdos, talvez assim as barreiras possam ser superadas ou minimizadas.

$\mathrm{O}$ registro do $\mathrm{P} 1$ ainda apresenta como limitação a organização curricular das disciplinas, que impede alterações nas práticas pedagógicas já estabelecidas: "Esbarra sempre nas questóes técnicas legais institucionais, o que dificulta [...]. Teria que ter uma certa modificação na estruturação das disciplinas, da carga horária para organizar isso". Desse modo, os docentes (P14 e P1) receiam a barreira organizacional, ou seja, as vias pelas quais se efetivariam os contatos dos acadêmicos com o futuro espaço de intervenção. Cabe destacar que "os currículos são elaborados e postos em prática por professores, que a seus modos, também carregam suas próprias concepçóes sobre o que é a Educação Física, que tipo de profissional ela deve formar e como esse profissional deve ser formado" $31: 51$. O currículo, e a organização das disciplinas ali posta, não impede que os professores estabeleçam seus próprios meios de formar os futuros professores. Modificar a estrutura das disciplinas demanda debates coletivos, e consequentemente, esforços individuais, contudo, é exequível.

Até aqui, é possível perceber que as limitaçóes institucionais referentes à universidade se centram: nas questóes de transporte e seguro; na incompatibilidade de turnos ou na concomitância de horários entre as instâncias de ensino; nos empecilhos burocráticos; e na inconsistência no acompanhamento aos discentes durante os encontros com as escolas.

Por outro lado, também existem os docentes certos de que não há limitações impedindo as açóes conjuntas entre a universidade e as escolas durante a formação inicial. Os exemplos: "não há limitação, a limitação cruamente dita, não há limitação, você precisa se adaptar a algumas estruturas para que você consiga fazer isso. Isso demanda tempo" (P2); "Eu não tenho percebido essas limitaçóes" (P3); "Eu não vejo uma limitação, eu vejo que se isso [práticas de docência] for uma proposta da disciplina, tiver uma programação dentro da ementa dos programas, dos critérios de avaliação, eu vejo que isso vai acontecer e é uma forma também de formação" (P11). $\mathrm{Na}$ perspectiva destes entrevistados, não há grandes restriçôes que inviabilizam ações mais próximas do contexto escolar. Desse modo, em função dos desafios e problemas existentes no contexto universitário, os docentes buscam caminhos para intervençôes diferenciadas ${ }^{32}$.

A Professora 13 ressalta a flexibilidade da universidade para certas propostas pedagógicas: "Aqui na universidade eu vejo uma abertura muito grande, por exemplo, se algum professor da rede pública municipal ou estadual quiser participar de algum projeto [...] ele pode, não há nenhum impedimento". Conforme Iza e Souza $\mathrm{NeTO}^{11}$, a parceria entre escola e universidade pode indicar a relação de reciprocidade possível entre as duas instituiçóes produtoras e formadoras de conhecimento. Mais particularmente, o P10 pontua ser leviano afirmar que " $A$ instituição te limita ou te encoraja", pois destaca que a Instituição de Ensino Superior é formada por pessoas, que por sua vez se relacionam no campo universitário conforme suas concepçóes e objetivos neste espaço social, deste modo, nem sempre as normas (geradores de limitaçóes e/ou novas possibilidades) institucionais refletem na viabilidade de boas práticas pedagógicas.

\begin{abstract}
Eu acho que depende muito da forma como o professor se coloca em relação à estrutura [...], da posiçẫo que ele situa a sua prática pedagógica no campo. [...] a estrutura no sentido universitário, as estruturas muitas vezes nos encorajam a coisas que näo importam, muitas vezes coisas que importam elas nos limitam [...]. Quando se fala em instituiçâo, muitas vezes a gente esquece que são pessoas que estão por detrás das instituiçōes, são relaçôes sociais por detrás das instituiçốes. Então são determinados agentes, determinadas pessoas que têm as suas concepçōes e elas vão defender aquilo, não porque elas julgam mais adequadas, mas é porque elas entendem que aquilo é necessário para marcar sua posição, a arte de dominar [...]. Dentro das gestöes universitárias as pessoas não reconhecem o mérito de determinadas propostas, ou quando elas assumem uma posição de comando, uma posição de poder, elas dão um jeito de construir outra concepção pedagógica, de propor outro projeto, justamente porque são açốes que marcam e legitimam a sua posição, aquilo que elas fazem. Tềm algumas coisas que seriam muito interessantes de serem mantidas, independentemente dessa oscilação das posiçóes de poder, mas infelizmente não é o que acontece (P10).
\end{abstract}

O Professor busca explicar como as limitaçóes ou possibilidades institucionais são permeadas pelos 
conflitos do campo universitário, que incluem seus agentes e os respectivos interesses neste mesmo espaço social. As posições ocupadas no campo são variáveis, e parte delas permite certas deliberaçôes, que refletirão no dia a dia profissional de outros agentes, que por suas posições (e disposições) podem acatar ou ignorar definiçóes gerais que ora contribuem, ora fragilizam iniciativas pedagógicas diferenciadas que almejam qualificar o processo de formação inicial.

Em pesquisa realizada por NeIRA ${ }^{19}$, cujo objetivo foi analisar os currículos da formação inicial em educação física a fim de obter explicações com respeito ao chamado 'choque de realidade', o autor argumenta que:

[...] a criação e existência de disciplinas, o momento em que configuram na grade e, até mesmo, os conteúdos trabalhados, muitas vezes, partem de decisões pessoais ou burocráticas. Não raro, procuram atender as disponibilidades, idiossincrasias e pressóes provenientes daqueles com maior poder de influência. Em muitos casos, determinados conhecimentos e atividades de ensino constam do currículo da Licenciatura sem qualquer justificativa científica ou formativa. Certo tema, evento, forma de avaliação ou conteúdo se fazem presentes porque o coordenador ou professor da disciplina assim o quis ${ }^{19: 58}$.

Parece que o registro do P10 vai ao encontro dessa argumentaçáo de NeIrA ${ }^{19}$, pois ambos demonstram como se moldam e solidificam as relaçóes de dependência no campo universitário, que ora enriquecem a formação profissional e ora fragilizam o processo. Nesse sentido, as intervençôes docentes não são totalmente autônomas, pois parte delas demanda autorização e consenso do grupo de professores (ou pelo menos daqueles que estão nos cargos administrativos). Contudo, espera-se que os objetivos formativos se sobressaiam em relação aos interesses individuais (independente se estejam vinculados às disciplinas ou a outras atividades acadêmicas), com intuito de transpassar as barreiras. Apesar dos esforços empenhados nessa ação, e considerando todas as tarefas já destinadas aos docentes na universidade, estratégias podem ser pensadas e efetivadas na tentativa de eliminar ou enfraquecer as limitações institucionais. Contornar os vieses é possível, conforme declaraçóes, tanto dos professores que apontaram problemáticas e possível soluçóes como dos que afirmaram não haver grandes restriçóes para aproximar os ensinos básico e superior.

\section{Universidade}

Quando questionados a respeito das limitaçóes e possibilidades institucionais envolvidas nas iniciativas de aproximar escolas e universidade no curso de licenciatura em educação física, os entrevistados relataram situações provenientes não só do ensino superior, mas também da educação básica, que apresenta características próprias, as quais podem atrasar ou impulsionar certas práticas pedagógicas dos licenciandos no ambiente escolar.

As dimensões que envolvem os limites abarcam: a burocracia requerida pela Secretaria Municipal de Educação; a resistência dos professores que atuam nas escolas em receber os acadêmicos de licenciatura em educação física; a restrição sofrida pelos licenciandos no ambiente escolar; e a incompatibilidade de horários. As outras dimensóes que remetem às possibilidades institucionais são a flexibilidade e a receptividade das escolas em receber acadêmicos para desenvolver práticas pedagógicas neste contexto.

Sobre as questóes organizacionais e burocráticas requeridas pela Secretaria de Educação - SEDUC, o A28 aponta: "Às vezes a Secretaria tem muita burocracia e acaba atrapalhando, mas acredito que tem uma relação boa [entre escolas e universidade]". Os comentários da P8 e P14 exemplificam mais detalhadamente essa questão.

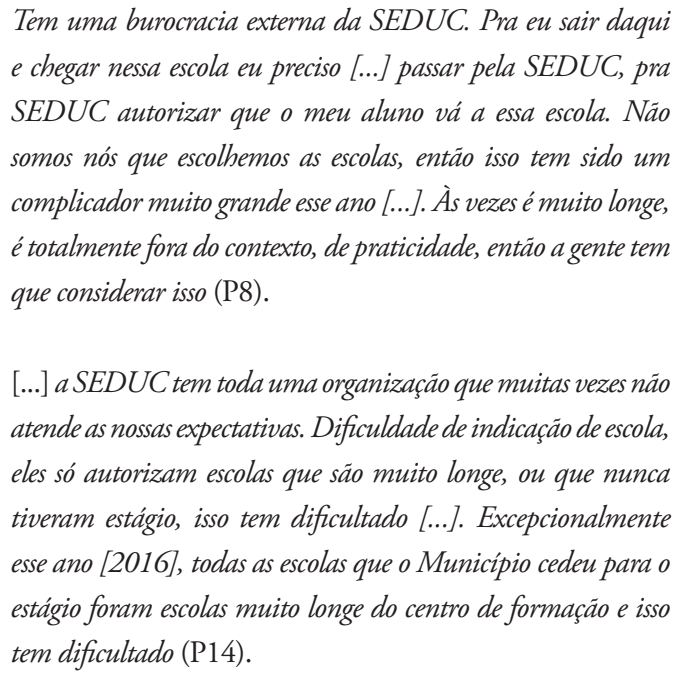

[...] a SEDUC tem toda uma organização que muitas vezes não atende as nossas expectativas. Dificuldade de indicaçâo de escola, eles só autorizam escolas que são muito longe, ou que nunca tiveram estágio, isso tem dificultado [...]. Excepcionalmente esse ano [2016], todas as escolas que o Município cedeu para o estágio foram escolas muito longe do centro de formação e isso tem dificultado (P14).

Os fragmentos revelam que a Secretaria de Educação delimita as escolas que podem ser frequentadas nos estágios obrigatórios, e expressam esse elemento como uma barreira no curso. Desse modo, as duas professoras (P8 e P14) pontuam especificamente a distância entre as escolas definidas pela Secretaria e a universidade como um obstáculo, pois nem sempre as escolhas atendem as expectativas dos acadêmicos. Apesar de esta ser mais uma questáo organizacional do que estritamente pedagógica, as entrevistadas citam como uma limitação 
institucional da educação básica, que não contribui no estreitamento das relaçóes com o ensino superior. Cabe ponderar também, que essas questóes podem variar conforme a gestão que está à frente da Secretaria.

Em pesquisa realizada por Montiel e Pereira ${ }^{4}$, em que um dos objetivos foi identificar os problemas evidenciados no desenvolvimento do estágio, os autores destacaram a burocratização desse processo, pois se observou certa dificuldade em encontrar escolas para a realização dos estágios, além do fato de que muitas escolas estabeleciam inúmeras exigências para fechar o contrato de estágio com a Instituição de Ensino Superior.

Por outro lado, a P13 pondera que as exigências da Secretaria de Educação ou do Núcleo Regional de Educação são necessárias, e justifica:

Para um aluno desenvolver uma pesquisa ou desenvolver um trabalho na escola, em qualquer escola, seja no Município ou no Estado, existe todo um cuidado do Núcleo e todo um cuidado da Secretaria de Educação do Município para a análise da possibilidade de desenvolvimento daquela pesquisa, daquela prática pedagógica. Eu acredito que a preocupação seja grande [...] como ele vai atuar com essa criança, se tem auxilio da visão de algum orientador. Eu vejo que essa administração, que é muito burocrática, de ter que levar projetos, ter que discutir, apresentar, esperar autorização, eu acho que é necessário. $O$ ambiente escolar é um ambiente de educação, de formação do sujeito, então tem que ser uma coisa bastante organizada epensada (P13).

A Professora argumenta pela defesa do planejamento e da organização das açôes que, de algum modo, proporcionam a inserção dos acadêmicos no âmbito escolar. Nessa perspectiva, os cuidados delimitados pelas instituiçôes da educaçấo básica são inerentes aos processos de articulação com o ensino superior. Conforme destaca P13, o ambiente educativo, que integra sujeitos em idade escolar, requer prudência nas atividades pedagógicas, inclusive daquelas que envolvem sujeitos externos à rotina das escolas. Esse debate precisa ser amplificado para rompimento com a ideia de ser algo meramente burocrático, visto que, de acordo com Ferraço e Alves ${ }^{33}$, podem surgir projetos de pesquisa que não levam em consideração a complexidade existente que envolve a comunidade escolar. Sendo, portanto, necessário entender a escola como espaço de formação para os licenciandos, mas antes, é indispensável reconhecêla como uma instância de ensino que exige cautela no decorrer das intervençóes.

Mesmo que nas questóes organizacional e burocrática o estágio supervisionado do curso de licenciatura em educação física ocupe espaços de críticas, sob a ótica dos entrevistados, este também desempenha o papel de referência para a consolidação de relaçôes mais articuladas entre os ensinos básico e superior.

$\mathrm{Na}$ perspectiva dos entrevistados, outra limitação direcionada à escola para aproximá-la do campo universitário diz respeito à resistência em receber acadêmicos, conforme mencionou o P5: "A gente observa que os professores da escola não gostam de lidar com os licenciandos que vêm das universidades". A P6 corrobora essa colocação, citando: "A gente consegue autorização em nivel mais amplo, mas chega na escola temos que ter um convencimento muito grande". P12 acrescenta: "Eu não sei se seria aberto da escola pra universidade. Depende do número de alunos". As afirmaçóes indicam certa relutância das escolas em receber os acadêmicos de licenciatura em educação física, contudo, os próprios entrevistados apresentam possíveis justificativas para essa limitação, conforme os fragmentos a seguir:

\begin{abstract}
Há uma dificuldade muito grande, e a justificativa é que nós não conseguimos acompanhar os alunos como nós deveríamos. Então nós temos que mostrar que nós não temos um número de professores suficiente pra fazer isso. Então essa é a maior limitação (P6).

Eu não sei, porque eu nunca tentei ir [à escola] sem que fosse com o estágio ou alguma coisa assim, então eu não sei se tem dificuldade. Eu sei que, por exemplo, no estágio têm algumas escolas que não aceitam estagiários [...] Ou às vezes dentro da escola têm professores que não aceitam estagiários [...] talvez a dificuldade seja (...) alguma coisa que aconteceu antes, com alunos anteriores, e ai os professores não querem mais (A3).
\end{abstract}

Apesar de expor como barreira o fato de existir resistência em receber licenciandos nas escolas, a P6 afirma que um dos motivos é a fragilidade no acompanhamento dos docentes universitários no decorrer do estágio supervisionado. Além disso, a A3 aponta, como uma possível justificativa para essa barreira, algum problema que porventura tenha ocorrido durante o estágio que refletiu negativamente em outras colaboraçóes entre a escola e a universidade, pelo curso de licenciatura em educaçâo física. Para Souza Neto, Sarti e Benites ${ }^{34: 315}$, "os estagiários tendem a ser recebidos nas escolas como alunos da universidade e não como futuros professores", e esse pode ser um dos motivos para situaçóes de resistência na parceria entre as instâncias de ensino. Ainda, as restriçốes durante o ensino nos estágios incluem, entre 
outros elementos, a ausência de supervisão adequada e o fato de os estagiários sentirem-se como estranhos na organização escolar ${ }^{14}$. Na perspectiva da A4,

Tem escola que te abraça, mas tem escola que te exclui. Então é bem diferente. Na escola em que estamos agora não, ela [professora supervisora] chama a gente para a reunião, para elaborar alguma coisa. Agora, nas outras não, era totalmente excluido. Eles faziam, mostravam pra gente: 'É isso que vocês têm que fazer e pronto'.

Novamente é possível perceber como as impressões dos acadêmicos e professores têm forte vínculo com as açóes do estágio supervisionado, apesar de o ponto gerador da discussão remeter, de modo mais geral, às possíveis limitaçóes e possibilidades imbricadas nas inter-relaçóes entre a universidade e as escolas. Quando a A3 admite que seu contato com a escola se deu unicamente por meio do estágio, parece revelar que não é possível responder ao ponto indagado sem ser por meio de exemplos do estágio. Essas frequentes recordações da experiência com o estágio podem indicar que, de fato, este componente curricular oferece aos envolvidos a oportunidade de uma convivência acadêmica extremamente enriquecedora ${ }^{35}$.

Apesar de mencionarem o estágio em detrimento de outras práticas pedagógicas diferenciadas, os fragmentos até aqui expostos revelam conflitos que permeiam a relação entre a universidade e as escolas, os quais podem, inclusive, prejudicar futuras propostas de articulação entre estas instâncias por meio de outras estratégias, por exemplo, a Prática como Componente Curricular ${ }^{g}$.

Ainda, outra dimensão que diz respeito à limitação para aproximar as comunidades, escolar e universitária, é a incompatibilidade de horários. P1, P2 e P13 mencionam a dificuldade para os professores das escolas desenvolverem alguma atividade pedagógica em suas aulas:

\footnotetext{
Já houve momentos em que eu trouxe [professor da escola para participar da disciplina]. A única limitação é a disponibilidade do professor no horário exato da aula. Eles são convidados quando têm palestras para vir, como se fosse um evento, é mais fácil no evento. Para a sala de aula, eu fiz algumas tentativas, algumas eu consegui, mas não é fácil por conta do horário. A maioria tem dois padröes no Estado, não coincide a horaatividade com a horalaula. São essas [limitaçôes] que eu senti, mas é viável sim (P1).
}

Há um problema da escola para cá. [...] o professor lá, a horaatividade dele não é tão grande assim, então não dá para tirar

\begin{abstract}
ele a qualquer momento, muitas vezes a compatibilidade do seu horário de aula com o horário dele é dificultada. Então eu acho que [...] essa conexão com a disponibilidade dele, a possibilidade da direçâo dele liberar e vir para cá (P2).
\end{abstract}

Justamente por conta do horário dele lá. É dificil sair no horário da atividade deles, dispensar alunos, por exemplo, ou botar um professor substituto para ele estar aqui acompanhando. Essa possibilidade é uma limitação, mas é uma preocupação com o desenvolvimento organizado da atividade lá na escola na qual ele trabalha (P13).

Salientamos que é preciso atentar para o fato de que os professores que atuam em escolas possuem carga horária de trabalho definida e se planejam para cumprila, de modo que interferir nessa organização pode ser uma tentativa árdua, haja vista as múltiplas tarefas envolvidas na rotina profissional desse professor. Ao analisar as produçóes científicas que abordam a temática do estágio supervisionado na formação de professores de educação física, Isse e Molina $\mathrm{NetO}^{27}$ indicaram que as pesquisas apresentavam experiências em diversos contextos escolares e destacavam a complexidade da ação docente, além de expor o estágio como uma possibilidade de os licenciandos refletirem sobre as condiçóes de trabalho do professor, oportunidade que também se dá por meio de outras estratégias, como as práticas curriculares e os projetos de pesquisa e extensão.

Apesar das limitaçóes expostas, também há consideraçóes que revelam as possibilidades existentes nas escolas para integrar os acadêmicos ao seu futuro espaço interventivo no decorrer da formação inicial. O A16 recorda das escolas que frequentou durante a graduação (como aluno do PIBID ou como estagiário) e afirma:

\footnotetext{
A escola - como a escola que eu trabalhei - é totalmente bemvindo. Se tivesse um projeto desses [de aproximar a escola da universidade] era totalmente bem-vindo. Eu não sei as outras. Mas eu acho que não teria resistência dentro da escola. Se você apresentasse um projeto, conversasse, mostrasse os objetivos, acho que seria interessante, porque os próprios professores iriam gostar, os próprios professores de educação fisica iriam gostar (A16).
}

O discente pensa ser possível desenvolver atividades pedagógicas no ambiente escolar, em que os licenciandos poderiam vivenciar este contexto. Baseando-se nos espaços já frequentados por ele como professor em formação, o A16 afirma que as escolas não apresentariam resistência em aceitar projetos articuladores com a universidade, desde que sejam açóes planejadas e com objetivos bem definidos, de modo 
que a proposta seja apresentada à comunidade escolar. No mesmo caminho, o A21 corrobora a provável receptividade das escolas às atividades universitárias:

[...] o professor estando com a gente na escola, levando para aplicar um conteúdo diferenciado, acho que a escola até aceitaria melhor, porque os alunos teriam materiais diferentes, conteúdos diferentes, nós iríamos aplicar coisas que eles nunca viram na vida, parkour, slackline, escalada, esporte de aventura, skate. $\mathrm{Na}$ escola não existe isso [...] seria diferente, eu acho que os alunos aceitariam muito fácil (A21).

Há a justificativa de que a receptividade seria positiva, pois as práticas pedagógicas dos acadêmicos nas escolas podem ser enriquecedoras para os alunos deste espaço social, que participariam de atividades diferenciadas. Além deste aspecto, é apresentada a questão do acompanhamento, que na perspectiva de A21 seria favorável para a anuência da escola em receber os discentes, já que haveria um docente responsável pelo acompanhamento da atividade. De acordo com Iza e Souza Neto 11:82, "A reflexáo partilhada entre pares da universidade e da escola pode contribuir para a aprendizagem da docência, e a universidade tem papel fundamental na mediação desse processo, podendo promover um diálogo com a escola”. Nesse sentido, os caminhos percorridos na ponte entre a Universidade e as escolas podem levar a contribuiçóes acadêmicas e pedagógicas para os envolvidos - professores de ambas as instâncias de ensino e discentes, além dos alunos que participam das aulas de Educação Física.

Ainda destacando as possibilidades institucionais, cabe expor a visão da P4 sobre o exemplo de parceria com professores da educação básica:

[...] eu conheço todo mundo de lá [da escola], eu já tenho a porta aberta. Só que a gente tem que tomar muito cuidado, porque os alunos, alguns extrapolam [...] eles vêm, você convida uma professora ela vem. [...] Através de palestras eles vão saber

\section{Considerações Finais}

Para compreender os elementos que impulsionam ou retardam a efetivação das práticas curriculares ou de outras açóes que permitem o contato acadêmico com o contexto escolar, foi necessário questionar os professores e discentes sobre os condicionantes que envolvem universidade e escola durante essas propostas. Nessa averiguação foram constatadas mais limitaçóes do que possibilidades nas iniciativas de

$$
\begin{aligned}
& \text { o que está acontecendo na escola [...], elas têm aquela vontade } \\
& \text { de mostrar o trabalho que fazem. }
\end{aligned}
$$

Fica claro que as atividades conjuntas entre a universidade e as escolas são facilitadas quando já existe certa proximidade entre os professores de ambos os espaços de ensino. No exemplo exposto por P4, suas aulas contaram com a participação de professores que atuam na educaçáo básica, de modo que estes foram às aulas no ensino superior partilhar e ensinar elementos de sua rotina profissional. A A12 também mencionou um exemplo de parceria entre professores das duas instâncias de ensino: "Esse ano, no estágio, tinha duas professoras responsáveis, elas marcaram reunião em todos os colégios, foram até o colégio [...] eu achei bem interessante porque elas trocaram e-mails, conversaram, a escola foi bem receptiva". Apesar de o registro remeter ao estágio, em que contatos entre os professores envolvidos na ação são inerentes ao processo, esse é um exemplo de como a proximidade é possível e produtiva, com esforços mútuos para estreitar a comunicação e estabelecer parcerias a fim de consolidar certas estratégias pedagógicas.

Acerca da subcategoria 'escola' e as possibilidades e limitaçóes vinculadas a ela, que podem estar interferindo (positiva ou negativamente) nas iniciativas e projetos que almejam uma relação de colaboração entre os ensinos básico e superior, vale destacar que as impressóes dos entrevistados estão fortemente baseadas nas experiências do estágio, o que pode indicar que este é o componente curricular mais consolidado no curso de licenciatura em educação física que insere os acadêmicos no âmbito escolar. Mesmo assim, os fragmentos expostos esclarecem a perspectiva discente e docente sobre os condicionantes envolvidos em possíveis outras propostas para integrar os licenciandos ao seu futuro espaço interventivo, ainda no decorrer da formação inicial.

aproximaçáo com a realidade de intervençáo durante a formação inicial. As principais barreiras incluem o seguro demandado nas atividades que extrapolam o campus universitário, a incompatibilidade de horários nos ensinos básico e superior, bem como as exigências da Secretaria de Educação para trabalhos acadêmicos realizados na educação básica. Há aqueles que não reconhecem dificuldades nesse processo e 
quem afirme existir flexibilidade por parte das escolas para receber licenciandos em exercício de docência. Além disso, os resultados revelam que as perspectivas discente e docente sobre essas questóes institucionais estão fortemente vinculadas às atividades do estágio supervisionado, o que pode evidenciar a carência de outras práticas pedagógicas no curso de Licenciatura em Educação Física.

Os professores atuantes do ensino superior e na educação básica, partilham do fato de serem, ao menos parcialmente, dependentes de certas decisóes originadas em comissóes específicas responsáveis por criar normas institucionais e acompanhar seu cumprimento, a fim de encaminhar ordenadamente os trabalhos. Contudo, diálogos são possíveis entre estes agentes, com o objetivo de propor e efetivar açóes de articulação para estruturar a ponte entre universidade e escolas, além de possibilitar que a formação inicial dos futuros professores de educação física se dê, de fato, em ambos os espaços formativos. Entretanto, neste caso, a iniciativa partirá do curso de graduação e demandará abertura das escolas.

Entre outros elementos, universidade e escola partilham da formaçáo de professores, e este fator comum carrega parte dos conflitos de ambos os espaços sociais, que inclui questóes burocráticas envolvidas nos percursos que os interligam e por onde passam os acadêmicos. Portanto, lidar e contornar as barreiras que impedem ou retardam a movimentação nessa ponte que permite o acesso de via dupla às instâncias de ensino e formação, são intervenções que dependem tanto do campo universitário quanto da escola. Ainda, esse envolvimento dos agentes depende do reconhecimento desses deslocamentos no decorrer da graduação, isso significa que os professores dos dois espaços necessitam compreender e defender a constância e o aprimoramento das iniciativas que integram os licenciandos ao cenário de intervenção docente. Além disso, esse reconhecimento possivelmente implicaria em fraturas de outras barreiras destacadas, como a resistência em receber os acadêmicos nas escolas e o acompanhamento docente no decorrer das práticas pedagógicas.

Criar rupturas em um sistema de ensino que por vezes apresenta mais limitaçóes do que possibilidades enriquecedoras para a formação inicial de professores requer persistência dos envolvidos, que envolve o reconhecimento de práticas diferenciadas e leva a diálogos entre os agentes do campo universitário e da comunidade escolar. Nesse sentido, são rupturas necessárias, as quais inicialmente podem desestabilizar atividades curriculares organizadas e sólidas em seus propósitos formativos, mas que posteriormente podem reestruturar esse mesmo formato curricular e torná-lo mais atraente para os grupos discente e docente.

Na obra de Pierre Bourdieu e Jean-Claude Passeron ${ }^{1}$ há reflexôes aprofundadas acerca do que os autores entendem serem os mecanismos de reprodução nos sistemas de ensino, e por meio de esquemas complementares, revelam (e denunciam) elementos pouco perceptíveis aos agentes integrantes desses espaços sociais. Ao conhecer a realidade escolar de perto, o licenciando terá elementos para desconfiar das intençóes da ação pedagógica, e em sua atuação poderá ter práticas diferenciadas. Entretanto, caso a formação inicial não proporcione estratégias que permitam ao futuro professor conhecer os conflitos do seu próprio ambiente de trabalho, esses professores possivelmente terão uma perspectiva limitada e superficial do cotidiano escolar.

Se considerarmos que a qualidade do trabalho docente depende, em grande parte, da formação inicial que recebem os futuros professores de Educação Física, é possível afirmar que, em longo prazo, rupturas que provoquem práticas pedagógicas diferenciadas na graduação poderão refletir positivamente na intervenção docente e talvez criem fraturas no sistema de ensino - na universidade pelas mudanças curriculares e nas aulas de educação física escolar, que contarão com professores integrados a este contexto, cientes de parte dos conflitos que o permeiam, e por isso mesmo, confiantes em relação aos seus objetivos e às suas estratégias pedagógicas enquanto docentes.

\section{Notas}

a. Disciplina(s); conteúdos da(s) disciplina(s) e a relaçáo com a escola; limitaçóes institucionais e visitas às escolas; limitaçóes institucionais e os professores da educaçáo básica na universidade; carga horária da(s) disciplina(s) e vivências nas escolas; A prática como componente curricular (PCC) e a aprendizagem dos conteúdos; a PCC e as outras açóes de aproximação entre a universidade e a escola; a PCC e as dimensóes da competências; a PCC e a formação inicial em educação física - licenciatura; outras consideraçóes.

b. Vivências/observações nas escolas; percepção dos conteúdos na realidade da escola; conhecer a rotina da educação 
básica antes do estágio curricular supervisionado (ECS); relação entre a PCC e o ECS; dimensôes da competência docente; relação teoria-prática no curso de licenciatura em educação física; relação universidade-escola; termo "prática como componente curricular"; outras consideraçôes.

c. Vale destacar que os tópicos dos roteiros direcionados à presente pesquisa foram: limitaçóes institucionais e visitas às escolas; limitaçóes institucionais e os professores da educaçáo básica na universidade (para os docentes) e vivências/observaçôes nas escolas; percepção dos conteúdos na realidade da escola; relação universidade-escola (para os discentes). Todavia, até pelo caráter de não rigidez da entrevista semiestruturada, há pontos levantados pelos entrevistados ao longo de toda a entrevista que também podem ter sido aqui considerados para aprofundar a discussão proposta.

d. Não serão expostas todas as unidades de registro relacionadas ao tema, mas aquelas representativas das impressóes que se destacaram nas entrevistas.

e. No segundo semestre de 2016 mais de mil escolas foram ocupadas em todo o Brasil contra a PEC 241 e a Medida Provisória que propóe a reforma do Ensino Médio. Disponível em: <http://www.cartacapital.com.br/blogs/ intervozes/a-cobertura-das-escolas-ocupadas-silencio-e-criminalizacao>. Acesso em: 07 fev. 2017.

f. Centros Municipais de Educação Infantil.

g. Na universidade investigada a Prática como Componente Curricular, exigida pelas Diretrizes Curriculares Nacionais para a formação de professores de 2015, não é desenvolvida.

\begin{abstract}
Institutional limitations and possibilities: the initial teacher training in Physical Education.

The aim was to verify the limitations faced by university professors and students of a degree in Physical Education to bring university and school closer together during the initial training, as well as the possibilities to integrate these institutions and contribute to the immersion of future teachers in basic education. It is a qualitative and descriptive research that was done from the case study in a public university of the state of Paraná, with 18 university professors and 41 students of the degree in Physical Education. All participants participated in a semistructured interview, whose content was investigated through content analysis supported by the NVivo 10 software. The presented perspective reveals that institutional barriers to qualify initial training through pedagogical activities integrated to the school environment are more than the existing possibilities for closer communication between primary and higher education levels. Even so, none of the records showed radicality; despite the barriers exposed, professors are predisposed to propose or incorporate formative proposals that are closer to the interventive reality of Physical Education teachers who work in the school setting.
\end{abstract}

KEYwoRDs: Physical Education; Teacher training; Teaching; School.

\title{
Referências
}

1. Bourdieu P, Passeron JC. A Reprodução: elementos para uma teoria do sistema de ensino. Petrópolis (RJ): Vozes; 2014.

2. Felício HMS, Oliveira RA. A formação prática de professores no estágio curricular. Educar Rev. 2008;1(32):215232.

3. Martiny LE, Gomes-da-Silva PN. "O que eu transformaria? Muita Coisa!": os saberes e os não saberes docentes presentes no estágio supervisionado em educação física. J Phys Educ. 2011;22(4):569-581.

4. Montiel FC, Pereira FM. Problemas evidenciados na operacionalização das 400 horas de estágio curricular supervisionado. J Phys Educ. 2011;22(3):421-432.

5. Antunes AC. A dimensão prática na preparação profissional em educação física: concepção e organização acadêmica 
[tese]. Campinas (SP): Universidade Estadual de Campinas, Faculdade de Educação Física; 2012.

6. Real GCM. A prática como componente curricular: o que isso significa na prática? Educação e Fronteiras OnLine. 2012;2(5):48-62.

7. Silva SAPS, et al. Atividades acadêmico-científico-culturais na formação profissional de educação física. Motriz. 2012;18(1):92-103.

8. Téo CE. Estágio curricular supervisionado como campo de pesquisa na formação inicial do professor de educação física da UEL [dissertação]. Londrina(PR): Universidade Estadual de Londrina, Centro de Educação, Comunicação e Artes; 2013.

9. Araujo RAS, Leitinho MC. Reflexóes sobre a prática como componente curricular do curso de licenciatura em educação física da universidade federal do maranhão. Motrivivência. 2014;26(43):89-103.

10. Clates DM, Günther MCC. O PIBID e o percurso formativo de professores de educação física. Motrivivência. 2015;27(46):53-68.

11. Iza DFV, Souza Neto SS. Os desafios do estágio curricular supervisionado em educação física na parceria entre universidade e escola. Movimento. 2015a;21(1):111-123.

12. Bisconsini CR, Oliveira AAB. O estágio curricular supervisionado na formação inicial para a docência: as significaçôes dos estagiários como atores do processo. Motrivivência. 2016;28(48):347-359.

13. Brasil. Ministério da Educação. Conselho Nacional de Educação. Resolução no 2, de 1 de julho de 2015. Define as Diretrizes Curriculares Nacionais para a formação inicial em nível superior (cursos de licenciatura, cursos de formação pedagógica para graduados e cursos de segunda licenciatura) e para a formação continuada. Brasília (DF); 2015.

14. Rikard G, Knight SM. Obstacles to professional development: interns' desire to fit in, get along, and be real teachers. J Teach Phys Educ. 1997;16(4):440-453.

15. Farias GO, et al. Preocupações pedagógicas de estudantes-estagiários na formação inicial em educação física. Motriz. 2008;14(3):310-319.

16. Rezer R, Fensterseifer PE. Docência em Educaçáo Física: reflexôes acerca de sua complexidade. Pensar a Prática. 2008;11(3):319-329.

17. Casey A, Fletcher T. Trading places: from Physical Education Teachers to Teacher Educators. J Teach Phys Educ. 2012;31(4):362-380.

18. Maffei WS. Prática como componente curricular e estágio supervisionado na formação de professores de educação física. Motrivivência. 2014;26(43):229-244.

19. Neira MG. Os currículos que formam professores de educação física e a Síndrome de Estocolmo: explicaçôes para o choque com a realidade. EFDeportes. 2014;33:51-71.

20. Silva Júnior AP. Configurações e relações estabelecidas no estágio curricular supervisionado na formação inicial de professores de educação física [tese]. Maringá (PR): Universidade Estadual de Maringá, Departamento de Educação Física; 2016.

21. Lüdke M, André MEDA. Pesquisa em educação: abordagens qualitativas. 2. ed. Rio de Janeiro: E.P.U.; 2013.

22. Bardin L. Análise de Conteúdo. São Paulo: Ediçôes 70; 2016.

23. Junges KS, Behrens MA. Prática docente no ensino superior: a formação pedagógica como mobilizadora de mudança. Perspectiva. 2015;33(1):285-317.

24. Cunha MI. O professor universitário na transição de paradigmas. Araraquara (SP): JM Editora; 1998.

25. Rios TA. Compreender e ensinar: por uma docência da melhor qualidade. São Paulo (SP): Cortez; 2010.

26. Souza Neto S, Silva VP. Prática como Componente Curricular: questôes e reflexôes. Diálogo Educ. 2014;14(43):889-909.

27. Isse SF, Molina Neto V. Estágio supervisionado na formação de professores de Educação Física: produções científicas sobre o tema. J Phys Educ. 2016; 27:1-16.

28. Iza DFV, Souza Neto SS. Por uma revolução na prática de ensino: o Estágio Curricular Supervisionado. Curitiba (PR): CRV; 2015b.

29. Saviani D. Sistema Nacional de Educação articulado ao Plano Nacional de Educação. Rev Bras Educ. 2010;15(44):380-392.

30. Anastasiou LGC, Alves LP. Processos de ensinagem na universidade: pressupostos para as estratégias de trabalho em aula. Joinville: Univille; 2015.

31. Alves CA, Figueiredo ZCC. Diretrizes curriculares para a formação em Educação Física: camisa de força para os currículos de formaçáo? Motrivivência. 2014;26(43):44-54. 
Bisconsini CR, et al.

32. Masetto MT, Gaeta C. Os desafios para a formação de professores do ensino superior. Revi Triângulo. 2012;8(2):413.

33. Ferraço CE, Alves N. As pesquisas com os cotidianos das escolas: pistas para se pensar a potência das imagens narrativas na invenção dos currículos e da formação. Espaço Currículo. 2015; 8(3):306-316.

34. Souza Neto S, Sarti FM, Benites LC. Entre o ofício de aluno e o habitus de professor: os desafios do estágio supervisionado no processo de iniciação à docência. Movimento. 2016;22(1):311-324.

35. Ghedin E, Almeida MI, Leite YUF. Formação de professores: caminhos e descaminhos da prática. Brasília (DF): Líber Livro; 2008.

\begin{tabular}{|c|c|}
\hline $\begin{array}{r}\text { ENDEREÇO } \\
\text { Camila Rinaldi Bisconsini } \\
\text { Rua Monsenhor Kimura, 323, Apto. } 103 \text { - Vila Cleópatra. } \\
\text { 87020-240 - Maringá - PR - Brasil } \\
\text { E-mail: camibisconsini@gmail.com }\end{array}$ & $\begin{array}{l}\text { Submetido: 05/ 07/ } 2018 \\
\text { Revisado: 26/ 10/ } 2018 \\
\text { Aceito: 21/ 04/ } 2019\end{array}$ \\
\hline
\end{tabular}

